\title{
Surkhet
}

\section{An Overview on ELT Scenario in Surkhet}

\section{- Dhirendra Prasad Sharma}

\begin{abstract}
The main purpose of this article is to analyze the ELT scenario of community based schools in Surkhet district. This paper, presents an introduction of ELT curriculum of English in school level, current status of ELT achievement in Surkhet district, issues, challenges and problems overwhelmed around ELT in community-based schools, strategies to enhance the competence and performance of teachers towards ELT for pedagogical recommendation and implication. From the close observation of some schools and teachers' class and official data related to ELT achievement, this article suggests that creating happy and child friendly environment towards learning second language, demand based trainings, use of relevant teaching aids in language classroom, effective continuous assessment system, monitoring, and awareness of the stakeholders towards English language teaching contribute a lot for making effective English classes in the context of Surkhet district.
\end{abstract}

Key words: ELT in Surkhet, learning outcomes, government aided community schools, English medium schools.

\section{Introduction}

English is a major international language, one of the six official languages of the United Nations (UN) and the means of international communication. It is a vital tool for all students to become successful in local, national and international communication. Undoubtedly, English is the means of communication globally. It is taught as a foreign language in all the schools of Nepal starting from Grade 1 and up to Grade 12. It is also taught as a compulsory subject up to the Bachelor level in different universities of the country. English has also been used as a medium of instruction in schools as per the provision made by the education regulations.

The introduction and development of English education in Nepal is closely connected with the establishment of Darbar School by Rana Prime Minister, Junga Bahadur Rana in 1910 B.S. Later, Chandra Shumser let the door of Durbar School open for common people. He also opened another English school at Patan. After the establishment of democracy in 1951, a number of schools and colleges were established throughout the country.

Nepal is no more isolated country from outside world. It has established diplomatic relations 
with more than 150 countries in the globe. In all its dealings with other nations, English is needed for it as an international language. Moreover, Nepal hosts a number of tourists every year. We need English to communicate with these visitors. Another factor for the need of English education is that many of the bilateral and multilateral agencies have been helping Nepal in its development providing with financial and technical aids. We need to deal with them. Likewise, the employments of Nepalese youth in abroad countries also boosted the importance of English language.

In spreading English education in Nepal, the contribution given by a number of English schools cannot be forgotten. Irrespective of their quality of education these schools have become very popular in our society. With the advent of English medium schools, the popularity of government schools has been overshadowed. As a result, community based schools are going to introduce English medium instruction to attack the pupils from private boarding schools and to improve the ELT situation gradually.

\section{Curriculum of ELT in school level and its implications}

The present school level English curriculum was introduced in Nepal in 1999 and it was slightly reorganized in the year 2007 seeing language as a skill that allows one to get things done through language functions. Primary level English curriculum has been designed for primary level education in Nepal, with a view to catering to the immediate needs of children learning English and building a basic foundation for their further studies in and through English. Moreover, it aims at developing a comprehensive communicative competence on the part of learners.
English being an academic language course should help students of the basic level of competency at grammatical, discourse, sociolinguistic and strategic level. The National Education Policy Commission (1992) laid a great emphasis on the regular updating and improvement of school curricula. The designation of the English curriculum is the result of this on-going process. Teaching English in schools (grade 1-12) has two main purposes: firstly, to enable pupils to exchange ideas with people of any nationality who speak or write English and secondly, to expose them to the vast treasures of knowledge available in both printed and electronic forms. The important features of the revised basic level (grade 6-8) curriculum are as follows:

1. The four language skills: listening, speaking, reading and writing are carefully graded and sequenced.

2. Common language competencies are set for basic level.

3. Language functions are presented with the emphasis on using them for communication.

4. Additional materials are sought for extensive practice.

5. Subject matters to practice the language skills are prescribed from broader spectrum.

6. Students' evaluation is expected to be based on the objectives of languages kills outlined in the curriculum.

7. A provision is made for alternative tests items for differently abled students.

This curriculum presents core competencies for the basic level. The learning outcomes are derived from the core competencies for all grades 
and presented in sequential order. These learning outcomes are categorized under language skills in gradual progression. A separate list of language functions for each grade has been presented with examples. Being a competency based curriculum, it anticipates that the assessment be based on the learners' performance. The skills are divided into four areas listening, speaking, reading and writing, although in practice it is impossible to isolate them in this way. Listening can be followed by speaking or writing, just as writing may follow listening or reading. Whatever may be the order all language learning aspects are to be practiced in compliance with the needs of the learners.

The secondary English curriculum has been prepared in order to make the Grade 9 and 10 courses more applicable to society, both in Nepal and outside world. Language here is seen as a skill that allows one to get things done. The things done through language are described as functions such as expressing likes and dislikes, good wishes, etc. Students are expected to internalize grammar rules naturally and use correct and grammatical language both in written and spoken expressions. English introduced at the primary level is much simpler than the English used at the secondary level. The functions remain the same at this advanced level but they are recycled with an increasing expansion of structure, vocabulary and register. To sum up, it is hoped that this curriculum expects to support, promote and strengthen the aspirations and interests of the nations.

\section{Current status of ELT in community- based schools in Surkhet district}

Surkhet is the headquarter and central part of the Mid-Western Region in Nepal. It has a municipality and 50 VDCs with $2451 \mathrm{sq} . \mathrm{km}$ area and 350,804 populations. In total, 123,970 students are studying in schools now in Surkhet district. There are 14 resource centers to provide the service delivery and support to the schools and teachers to enhance the quality education i.e. these are extended arms of the District Education Office. Altogether 521 schools are community based and remaining 89 schools are institutionalized schools which are providing English medium education in the district.

Teachers use the Nepali language as the medium of instruction in the government aided schools except English subject. Gradually, some of the schools are trying to use the English language as the medium of instruction to attack the pupils from private schools and support and enhance the quality education.

The demand based training for the English teachers in primary level is provided through resource centers using rooster and trainers, called Teachers Professional Development (TPD) Training. They sometimes support the teachers and provide feedback have the problem while teaching in their classroom. Lower secondary and secondary level English teachers have been trained through ETC, Surkhet. NELT branch Surkhet also supports to develop their proficiency by conducting training, conference, seminar, workshop and so on. The private schools in Surkhet use English textbooks published by different publishing houses whereas government schools use the textbooks of CDC at all levels. As a result all the students studying in government school across the country use the same textbooks.

The curriculum of primary level (grade 1-5) is designed in integrated way. All of the teachers 
appointed to teach at primary level should have the knowledge of all subjects and teach all subjects whether they have a good command or not. ELT in primary level is directly affected by such policy of the government due to the lack of language teachers. It always raises the questionCan all the teachers teach all of the subjects effectively in primary level? Do they have a good command over English language? Of course not. On the other hand, the quotas of the teachers are not proportionally appropriate on the basis of the number of the students. They manage their class by using different teaching schedules such as grade teaching, multi grade teaching, etc. A few number of the teachers should manage the teaching learning in the primary level - is another issues in the education system in Nepal. Surkhet district is not an exception of such issues.

ELT situation in lower secondary level (grade 6-8) and secondary level in Surkhet district is not full-fledged as well. The language teachers are not available in all schools due to the teacher management by the government and lack of local resources. The primary level teachers are teaching in lower secondary and secondary levels. They do not know in which level they have to teach. In some of the schools, the language teachers use traditional method viz. grammar translation method. Their teaching learning strategies are exam oriented rather than developing the competence and performance of the English language learners. They are always aware of getting better result on the part of the students. On the other hand, the English curriculum is designed integrating four skills of language. But the English teachers do not focus on listening and speaking skill in all grades. The classroom activities and practical test on listening and speaking is only taken as the completion of formality. The continuous assessment system, a formative evaluation is not understood and applied seriously by the language teachers in basic level. The appropriate teaching materials are not used by them properly to make their teaching effective.

The learning achievement of the students in Surkhet district in English subject in community schools of the Year 2070 is given in the following table:

\begin{tabular}{|l|c|c|c|c|c|c|c|c|c|c|c|c|c|}
\hline Grade & 1 & 2 & 3 & 4 & 5 & $1-5$ & 6 & 7 & 8 & $6-8$ & 9 & 10 & $9-10$ \\
\hline Average marks & 49.34 & 51.84 & 52.91 & 45.59 & 47.89 & 49.39 & 43.85 & 37.60 & 45.24 & 42.31 & 33.86 & 34.35 & 34.7 \\
\hline
\end{tabular}

Source: Flash II, 2070

From the above data, the achievement of the students in English subject in Surkhet district is not satisfactory. Approximately, students are getting below 50 marks in English subject in each Grade.

\section{Issues, challenges and problems of ELT in Surkhet}

English language teaching has grown as a big industry and profession. For several reasons EFL instruction often does not accomplish its objectives and leaves students without an adequate level of proficiency in English. Despite its long history, it has some issues and challenges. Some of them can be mentioned below:

1. Lack of well-trained teachers

2. Over-crowded large classes

3. Poor physical facilities of the academic institutions

4. Linguistically heterogeneous classes 
5. Inadequate professionalism in English teachers

6. Having mixed ability students in the ELT classroom

The major share of English language teaching in the world is in the hands of non-native speaker teachers and Surkhet is also not an exception. If there are no good sound management provisions and the teacher has to take every responsibility to manage the classroom. It is very difficult for them to handle the classroom activities. In almost every class, the number of students is at least more than 50. The students in the class are heterogeneous with different proficiency levels. Some can speak English and some cannot. At the same time language teaching is more challenging.

The teachers encounter high stress but are paid low salaries. English language teachers are not getting refereshment trainings according to the changes in the methodologies. Language teaching required an extensive amount of time, but the time provided for the instruction is not sufficient. Most of the community-based schools in Surkhet district do not have listening materials like cassettes, $\mathrm{CD}$ player, etc. The teachers are often not well trained to operate and use technology. The cultural and linguistic diversity of this district is another great challenge for ELT. The roles and status of the teacher and students are perceived differently in different culture. In Surkheti culture there is definite distance between teachers and students. This type of practices may function as a barrier for better learning. The globalization has brought English to all corners of the world and our country Nepal has also influenced by this language very much. Whatever the reason is, the condition or status of ELT in our government has brought new strategies for improving the academic and professional skill of untrained teachers.

The major problem of ELT in Surkhet is the use of students' mother tongue in the class. When a teacher makes his/her students practice in pairs or groups, students start speaking their mothertongue if the teacher is working with other pairs. In addition to it, some teachers who are used to using the GT (Grammar Translation) method find it easy to use students' mother-tongue in English classes. As a result, students are not exposed to English.

At last, the challenges and problems in ELT in Surkhet. But these problems can be solved in different ways. The teachers need to analyze the situations and find the apt solutions that can be properly used. There are a number of problems in ELT in Surkhet district. Some of them are given in the following points:

- Lack of the English language teachers in all schools in terms of the classes and the number of the students.

- Grammar translation method is emphasized i.e. the teachers mostly use the mother tongue of the students.

- Adequate teaching materials have not been constructed and used by the language teachers.

- Listening and speaking skills are less prioritized rather than reading and writing skills in the classroom.

- ELT in community based schools is always exam-oriented.

- The students' achievement has not been assessed through both of the assessment system viz. terminal and continuous assessment in basic levels effectively.

- The language teachers do not follow the 
inductive method of teaching grammar.

- The TPD trainings do not succeed to solve the problem of language teachers in all levels due to the lack of satisfying their right needs.

- Due to the lack of knowledge of curriculum, the language teachers use the textbook as a main tool of teaching and learning so that the teachers do not get the expected outcomes from the students.

- There is not a happy atmosphere to learn second language in the government schools due to lack of the ability of the teachers to create motivation in the classroom so that learners are interested to learn L2. and

- Modern language technology related to ICT has not been used by the language teachers.

\section{Pedagogical recommendations}

In order to cope with such issues and problems, teachers should think in a different ways. They need to find such strategies which will be fruitful and helpful for all types of teachers and learners of the language classroom.

- The relevant teaching materials should be selected, constructed and used properly by the teachers. Using different teaching aids in the classroom helps to motivate all the learners. Continuous evaluation of the learners helps teacher to identify poor learners so that they can improve them accordingly.

- Appeal to all senses, contingency plans, in-class activity, open ended plans, personalizing the tasks, games, competitions and dramatization, extra homework, portfolios, group-work activities, self -access centers, etc. are useful for ELT to improve students' study and motivate them towards learning in language classroom.

- Making plan, teacher's leadership, communication, the well managed classroom, creating a happy atmosphere, voice, effective presentation, chunking, verbal aspect, students' participation, positioning, posturing and movement, eye contact, gesture, correct pronunciation and evaluation should be implied in the language classroom.

- Grammar translation method should be less prioritized by the teachers so that the students can develop their competence and performance in English.

- NELTA branch of Surkhet should be considered as a role of umbrella organization to improve the quality of English education in Surkhet district.

- Status and working conditions of the teachers should be improved.

- Various technologies have been developed due to the result of the miraculous evolution of science and technology. So, these technologies should be used in teaching learning activities.

- The positive attitude and motivation of the students to learn L2 should be developed by the teachers using different varieties of strategies in the classroom for effective learning.

- The four language skills should be equally prioritized in the language classroom according to the time allotment prescribed by the curriculum.

- The home assignment should be given 
to the students daily.

- We should create happy and child friendly environment towards learning second language in our schools.

- The demand based training for the language teachers provided by DEO, Surkhet should be strongly implemented in the classroom because the qualification and personal qualities of the teachers are the components of effective teaching.

- The language teachers should use the curriculum while teaching and learning L2 and conduct the action research if they will have a problem in their language Class.

- The stakeholders should be aware of monitoring to contribute a lot for making effectiveness of ELT in the context of Surkhet district. and

- The forum including with all of the language teachers from primary to secondary level in this district should be made, unified them and mobilize them with the facilitation of NELTA Surkhet.

\section{Conclusion}

Teaching is a skill like any other skills. It can be acquired and refined with the help of methods and techniques peculiar to it. There are challenges for the teachers to deal with language classes because there is variety and teachers are worried in such cases. But if we try to apply the benefit of such classes and apply learner centered methods inside the classroom, it can be the easiest way to deal with stronger as well as weaker students. Teachers can apply different strategies for teaching four skills of the language, especially by specifying the different tasks for stronger as well as weaker students. The students should be well motivated for the exploration of new things and ideas.

A good teacher should be well informed to cope with such issues, challenges and problems related to teaching and learning L2 in the classroom. Communicative approach of language teaching should be emphasized by the teachers with well-equipped teaching aids in the classroom. The English language should be used as a means of instruction in the classroom so that the students can communicate in English. We should provide them equal opportunities to do the classroom tasks and develop their potentialities in and outside the classroom. English class should be fun using a variety of child centered and child friendly activities by the teachers. To sum up, we can minimize the issues and solve the problems which are threatening us while teaching and learning English in school level if we have a positive attitude towards teaching and language. The role of the language teachers should be as a well facilitator in the language classes.

\section{About the author \\ $M r$. Sharma is School supervisor of DEO Surkhet. He has taught compulsory and optional English from lower secondary to higher secondary level for more than ten years in Dailekh before his present designation. He instructs the English teachers in TPD training in RC level in Surkhet district now.}

\section{References}

Harmer, J. (2007). The practice of English language teaching. London: Pearson Longman.

Kochhar, S.K. (1985). Methods and techniques of teaching. New Delhi: Sterling Publishers Pvt. Ltd. 